\title{
Dyspepsia Among Young Conscripts: Correlations with Psychoemotional State and Eating Habits
}

\author{
A Giacosa, S G Sukkar, L Gogioso \\ Unit of Clinical Nutrition, National Cancer Institute, Viale Benedetto XV, 16132 Genoa, Italy
}

SUMMARY: The prevalence of dyspepsia was evaluated in 83 young conscripted soldiers: 38 of them were normally resident in the town where the barracks was sited (Genoa) while 45 came from different districts.

Dyspepsia was observed in $\mathbf{4 9 . 4 \%}$ of total cases, and there were significant differences in the incidence between the two groups. In 40 out of $\mathbf{4 1}$ cases, dyspepsia was of the functional type.

Psychoneurotic reactions were found in $69.8 \%$ of total cases and these reactions were closely correlated with the $\overparen{D}$ occurrence of dyspepsia both in soldiers who were local residents and those who were not. Dyspepsia could not however be correlated with eating habits, or with the consumption of alcohol, coffee or tobacco.

\section{Introduction}

The frequency of functional dyspepsia among the young population is not well known ${ }^{1,2}$ but dyspepsia does seem to be very common among young conscripts ${ }^{3}$.

The aim of this research is to assess the frequency of dyspepsia among a population of conscripted soldiers and correlate these data with the eating and smoking habits, with alcohol and coffee intake and with the psychoemotional state. The study has been done on subjects normally living in the same town (Genoa) where the barracks was located and on subjects coming from other towns.

\section{Materials and Methods}

Eighty-three subjects, from 19 to 27 years old, were examined: 38 were resident (RE) and 45 were not resident (NRE) in Genoa.

They had all been conscripted for between two and five months. They all belonged to the same barracks and were all symptomless at the time of conscription.

The subjects, in the barracks, were fed a standard balanced diet of $3000 \mathrm{KCal} / \mathrm{day}$, made up of carbohydrate $(2100 \mathrm{kCal})$, protein $(400 \mathrm{KCal})$ and lipid $(500 \mathrm{KCal})$.

After noting personal and anthropometrical data (weight, height, arm girth and triceps skinfold), the soldiers were interviewed using a questionnaire to evaluate:

(1) The psychoemotional state related to lifestyle before conscription, through questions specifically designed to discover psychoneurotic reactions (eg anxiety depression), adapted from the Minnesota Multiphasic Personality Inventory.

(2) The frequency of meals taken in barracks. Lunch and dinner only were considered. Thus 14 meals per week taken in barracks was the maximum possible.

(3) The frequency and places where the meals were consumed out of the barracks (eg home, restaurants, snacks).

(4) The number of cigarettes smoked/day, grammes of alcohol consumed/day, and cups of coffee taken/day.

(5) The presence of dyspepsia, distinguishing between epigastric pain, abdominal distension, nausea, $\vec{\sigma}$ vomiting, flatulence, eructation and pyrosis (heartburn). In the patients complaining of dyspepsia, X-ray and sonography of the upper GI tract were performed.

The statistical evaluation of the obtained data was done by means of the $X^{2}$ method.

\section{Results}

Dyspepsia was observed in 41 out of 83 subject studied $(49.9 \%$ ): symptoms appeared in $60.5 \%$ (23 oब T of 38 ) of the RE and in $39.5 \%$ (18 out of 45$)$ of the NRT $(\mathrm{P}<0.07)$ (Table 1). Among the $\mathrm{RE}$, abdomin $\mathrm{g}$ distension was found in $69.6 \%$, epigastric pain in $13.1 \%$ pyrosis (heartburn) in $21.7 \%$, nausea in $13.1 \% \overrightarrow{0}$

Table 1

Dyspepsia and Psychoemotional Reactions Among Resident and Non Resident Conscripts

\begin{tabular}{lccc}
\hline & Cases & Dyspeptics & Anxious \\
\hline $\begin{array}{l}\text { Resident } \\
(\text { RE })\end{array}$ & 38 & 23 & 24 \\
$\begin{array}{l}\text { Non Resident } \\
\text { (NRE) }\end{array}$ & 45 & 18 & 34 \\
Total & & & \\
\hline
\end{tabular}

vomiting in $4.3 \%$, flatulence in $10 \%$, and eructation in $5 \%$ : among the NRE abdominal distension was present in $66.6 \%$, pyrosis in $22.2 \%$, nausea in $33.3 \%$. vomiting in $11.1 \%$, flatulence in $22.2 \%$ and eructation in $11.1 \%$ of cases.

X-ray study of the upper digestive tract demonstrated the presence of a lesion in only one of the dyspeptic subjects, a 26 year old NRE with duodenal ulcer.

Psychoneurotic reactions have appeared during the of military service in 58 out of 83 cases $(69.8 \%)$, of which $N$ 24 were RE, and 34 were NRE $(P<0.7)$. (Table 1$)$. 
Number of cases

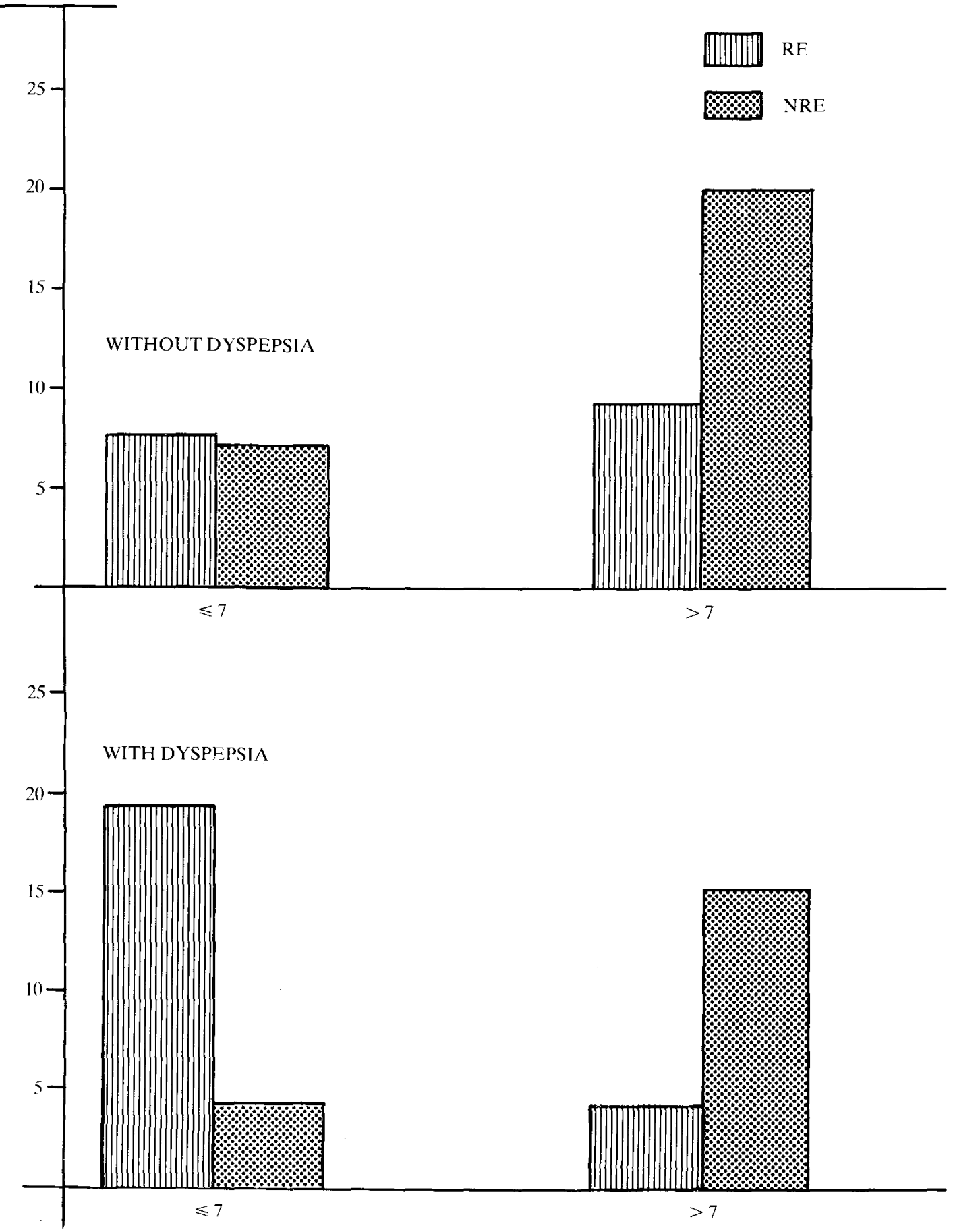

Fig 1. Correlation between dyspepsia and number of meals inside the barracks per week.

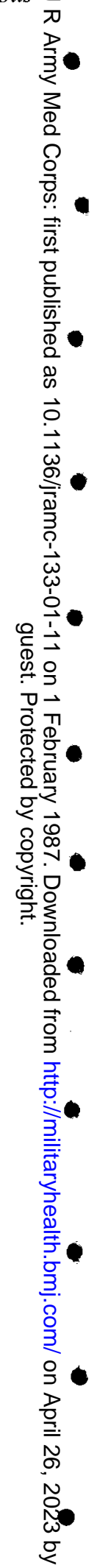




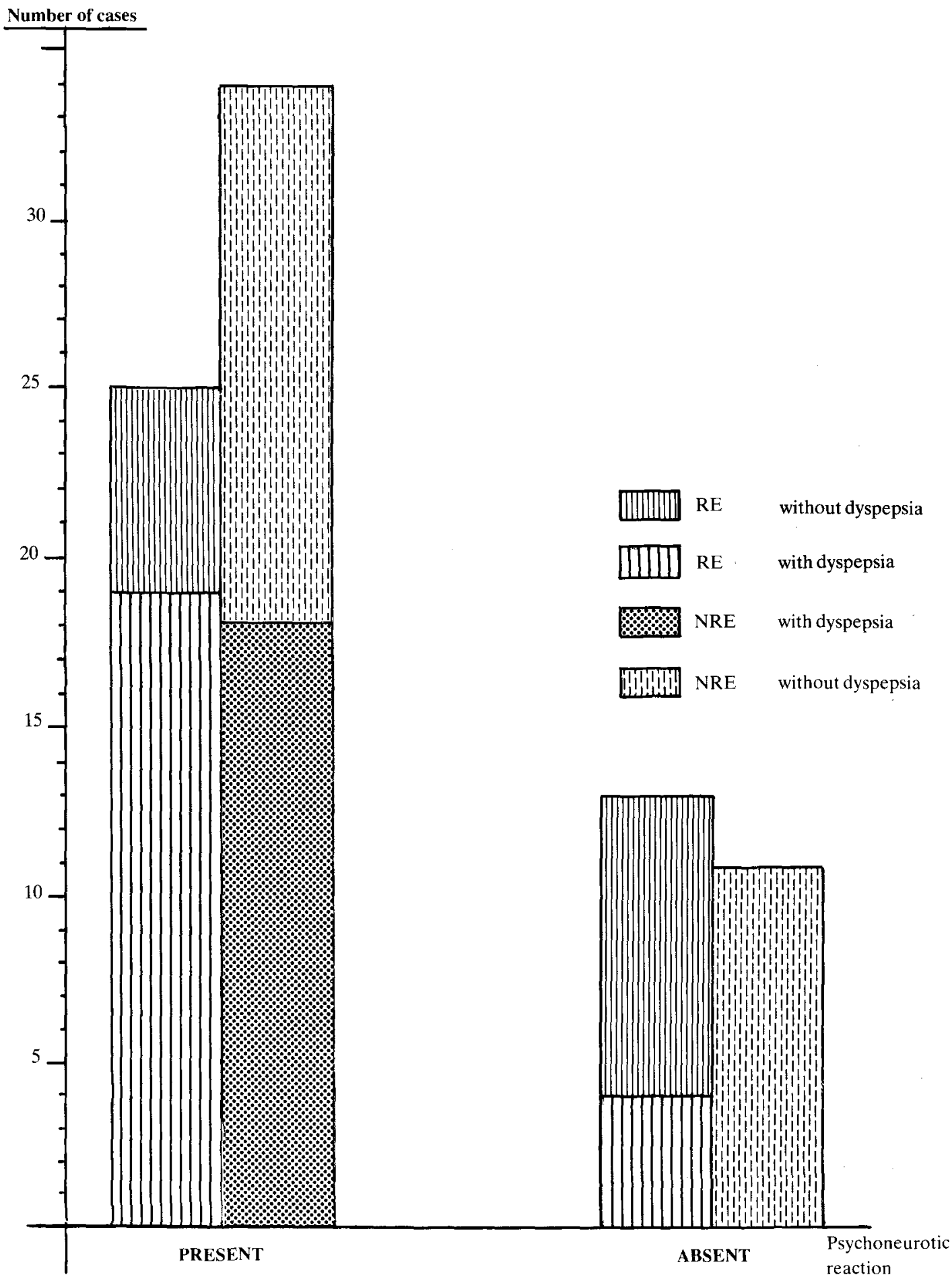

Fig 2. Correlation between psychoneurotic reaction and dyspepsia. reaction 
Concerning the other habits considered 25 out of 41 $(60.9 \%)$ of the dyspeptic patients usually drink at least $20 \mathrm{gr}$ of alcohol per day, while 22 out of $42(52.3 \%)$ of patients without dyspepsia also drink at least $20 \mathrm{gr}$ of alcohol per day.

$63.4 \%$ ( 26 out of 41 ) of the dyspeptics and $61.9 \%$ (28 out of 42) of the non dyspeptics drink more than a cup of coffee a day. Fourteen dyspeptics are non-smokers, nine smoke less than 10 per day, nine from 10 to 20 per day and nine more than 20 per day. Among the non dyspeptic patients 21 are non smokers, eight smoke less than 10 cigarettes per day, four between 10 to 20 per day, and nine more than 20 per day.

As far as these habits are concerned, there are no significant differences between the RE and NRE.

$50.6 \%$ of the examined subjects exhibited weight decrease $(3.5 \pm 2.2 \mathrm{~kg})$ after conscription; no significant weight variation (less than $1 \mathrm{~kg}$ ) was observed in $43.2 \%$ of the subjects, and $7.2 \%$ showed an increase in weight $(2.7 \pm 1.2 \mathrm{~kg})$.

The subjects were subdivided into those who took their meals mainly in the barracks, and those who took their meals mainly outside. 26 out of $38 \mathrm{RE}(68.4 \%)$ took more than seven meals per week outside, while $22.2 \%$ of the NRE ( 10 out of 45 cases) had their meals mainly outside. The RE consumed most of their external meals at home (23 out of 26) while the NRE took their "external meals" as occasional snacks (16 out of 10 cases) (Figure 1).

\section{Discussion}

The analysis of the collected data shows that dyspepsia is common among the conscripted soldiers; in fact, dyspeptic symptoms appeared in $49.4 \%$ out of the 83 studied cases after a period of time ranging from two to five months of military service (Table 1 ). The X-ray examination of the upper digestive tract of the symptomatic subjects suggests that this is predominantly "functional dyspepsia" (40 out of 41 cases). Only one case of duodenal ulcer was found on X-ray.

The comparison between the dyspeptic subjects who were usually resident in the same town $(60.6 \%$ of cases) where they were serving in the army, with the others who were not $(39.4 \%$ of the cases) shows a slight preponderance in the former group, although it was not significant from the statistical point of view $(\mathrm{P}<0.07)$.

The evaluation of the psychoemotional state revealed a high prevalence of psychoneurotic reactions in the population studied $(69.8 \%)$, with no significant differences between RE $(63.1 \%)$ and NRE $(75.5 \%)(P$ $<0.7)$. However, anxiety was more frequent among RE, while depression was found mostly among NRE.

These data agree with other observations ${ }^{4.5}$ which stress the conflict experienced by young reluctant conscripts, mostly due to the authoritarianism and other stresses of military life such as being unable to pursue one's normal career and interests.
Furthermore, the military environment, the boredom and interpersonal conflicts between individuals of differing age and cultural background inside and outside $z$ the barracks, reinforce these psychological reactions $s^{6,7,8} . \stackrel{\mathbb{2}}{2}$

The correlation between anxiety and dyspepsia was $\bigcirc$ particularly high; 37 out of 58 anxious soldiers were응

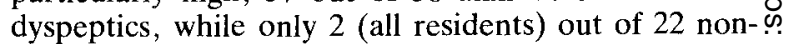
anxious ones were dyspeptics $(P<0.005)$, (Figure 2$)$. $\overrightarrow{\vec{B}}$ This confirms previous studies in which the relation $\stackrel{?}{+}$ between psychoneurotic reactions and functional? dyspepsia was observed ${ }^{9}$.

Conversely changes in eating habits, typical of $\frac{\infty}{\sigma}$ conscripted life, did not have much effect on the $\propto$ incidence of dyspeptic symptoms. In fact, dyspepsia was present to a similar degree in subjects who had their $\vec{\circ}$ meals mainly inside the barracks, and subjects who had $\rightarrow$ them mainly outside.

These findings underline the relationship between psychoreactive status and dyspepsia in young conscripts. Changes in eating habits seem to play a less important role. Additionally, no positive correlation between $\vec{\omega}$ dyspepsia and use of coffee, cigarettes or alcoholic drinks was demonstrated.

In conclusion, functional dyspepsia is very comm among young conscripted soldiers. The symptoms aque present to a similar degree in those living close to theif? homes, or far from their homes. Dyspepsia is closedy 7 related to common anxiety/depressive states, but is not related to eating habits, nor the use of cigarettes, alcoh का and coffee.

REFERENCES

1. BONNEVIE $O$. The incidence and result of radiologi@̊ examination of the stomach using a barium meal. Scand. $J$ Gastroenterol. 1976; 11: 839-847.

2. Adami H O, Agenas I and Gustavsson S, et al. Then clinical diagnosis of "Gastritis". Scand J. Gasteroenterol. 1984; 19: 216-219.

3. Glass A J. Current problems in military psychiatry. JAMA 1952; 150: 6-10.

4. Hollingshead A B and Redlich F C. "Classi sociali e $\overline{\overline{0}}$ malattie mentali". Giulio Einaudi Ed., Torino. 1972; 231-242.

5. KANDIC B and JovENIC M. Emotionally immature? personality and behaviour patterns in a military group. Vojnoned Akad Beograd Vojvosanit Pregh 1968; 25: 367-380.

6. Martella F, Antolini $G$ and Fratton S. Studio esofago-gastro-duodeno-scopico in giovani affetti $\mathrm{da} \overparen{D}$ disturbi riferibili a patologia delle prime vie digerenti. Giorn Med Mil 1982; 4-7: 386-390.

7. Melorio E. Aspetti psicopatologici ed ecologici delle 3 reazioni psicogene da disadattamento nel corso del: servizio militare di leva. Giorn Med Mil 1974; 4-5:윽 124-129.

8. Rademaker J, Le Febuie J and Huray J. Psychiatric음 reactions and the problem of adaptation to military $D$ service. Acta Belg de Art Med et Pharmac Milit. 1959;을 112: 131-135.

9. Berti Riboli E, Reboa $G$ and Arnulfo G. "La/ motilita" dello stomaco e del duodeno. Lombardo Ed., N Roma, 1984. 